\title{
A New Species of Echinosaura (Gymnophthalmidae) from Ecuador and Colombia with Comments on Other Members of the Genus and Teuchocercus keyi
}

\author{
ThOMAs H. FrITtS,,$^{1,2}$ ANA AlmENDÁRIZ, ${ }^{3}$ AND SisSI SAMEC ${ }^{4}$ \\ 'U.S. Geological Survey, Midcontinent Ecological Science Center, 4512 McMurry Avenue, \\ Fort Collins, Colorado 80525, USA; E-mail: frittstom@cs.com \\ ${ }^{3}$ Escuela Politécnica Nacional, Departamento de Ciencias Biológicas, Apartado 2759, Quito, Ecuador \\ ${ }^{4}$ Naturhistorisches Museum Wien, Burgring 7, A-1014, Wien, Austria
}

\begin{abstract}
A new species of the genus Echinosaura is described from the Pacific drainages of northern Ecuador and adjacent Colombia. Evaluation of variation among congeners justifies their recognition as distinct species instead of subspecies as previously proposed. The new lizard occurs in close proximity to Echinosaura horrida and Teuchocercus keyi.
\end{abstract}

RESUMEN.-Se describe una nueva especie de lagartija del género Echinosaura de los drenajes Pacificos en el norte de Ecuador y el sur de Colombia. Evaluación de variación entre las formas nombradas en el genero se justifica reconocimiento como especies distintas, y no como subespecies. La especie nueva ocurre cerca de las distribuciones de Echinosaura horrida y Teuchocercus keyi.

Lizards of the genus Echinosaura are distributed from Panama to the Pacific drainages of Ecuador. Four nominate forms have been described, but only a single species with three subspecies was recognized by Uzzell (1965). Subsequent to Uzzell's review, Teuchocercus keyi, presumably related to Echinosaura, was named by Fritts and Smith (1969). Although considerable material exists from Ecuador assignable to a single taxon (Echinosaura horrida), other taxa of this group remain sparsely documented. The present review was stimulated by our attempts to identify specimens of Echinosaura from the extreme northern regions of Esmeraldas and Carchi Provinces in Ecuador and adjacent areas of Colombia. We interpret these lizards as an undescribed species of the genus Echinosaura. Additional material of Echinosaura and Teuchocercus is now available to allow reexamination of morphological variation in the groups and a reevaluation of taxonomic and distributional relationships. The cephalic scutellation of this group is extremely variable both within and among taxa. This variation must be interpreted cautiously in assessing relationships within these lizards.

\section{MATERIALS AND Methods}

We have examined nearly all specimens of the genera Teuchocercus and Echinosaura available (Appendix 1) in the collections of the National Museum of Natural History (USNM), American Museum of Natural History (AMNH), Escuela Politecnica Nacional, Ecuador (EPN), Museum

${ }^{2}$ Corresponding Author. of Comparative Zoology, Harvard (MCZ), University of Kansas Museum of Natural History (KU), Academy of Natural Sciences, Philadelphia (ANSP), and the Naturhistorisches Museum Wien (NMW). We have also used data summarized by Uzzell (1965) to supplement samples available to us.

In an attempt to clarify the comparison of the members of this group and other poorly known microteiid groups, we have adopted a terminology for scutellation patterned after the definitions used by Peters (1964), which is somewhat at variance with that of Uzzell (1965), Oftedal (1974), and other recent workers (e.g., Harris, 1994; Kizirian, 1996). Acknowledging that the cephalic scutellation of lizards in the genera Echinosaura and Teuchocercus is variable and deviates from the typical gymnophthalmid patterns, we have attempted to avoid confusion by providing explicit descriptions to supplement names of scales if the identity of scales is not clear. Although many gymophthalmid lizards have only one scale or an additional pair of scales (typically called frontonasals and prefrontals, respectively) between the rostral and the frontal, Teuchocercus and Echinosaura specimens reported here have three series of scales in this region warranting careful description of scale positions and homologies. We have used the following definitions of the cephalic head scales.

Internasals.-The scales located between the rostral, nasals, and frontonasals (Peters, 1964: 170). In the genus Echinosaura the internasal may be paired or single. Uzzell (1965) used the 
terms internasal and frontonasal interchangeably in describing the scale immediately posterior to the rostral. This inconsistency is a potential source of confusion for students of this group of lizards.

Frontonasals.-The scale or scales located between the internasal, frontal, and loreal. In lizards with paired prefrontals, the frontonasal may be bounded posteriorly by the prefrontals or by the prefrontals and frontal instead of the frontal only (Peters, 1964:132). Normally the frontonasal is confined to the dorsal surface of the snout and largely anterior to the interorbital area.

Prefrontals.-Paired or single scales between the frontonasal and frontal, in some lizards, which occupy the anterior margin of the interorbital area. Prefrontals are usually absent in the genus Echinosaura but are variably present in Teuchocercus and some Echinosaura. In distinguishing prefrontals from frontonasals, prefrontals are nearly as wide as long because they occupy the area where the head expands to accommodate the orbits, whereas frontonasals may be longer than wide and primarily confined to the snout anterior to the interorbital area.

Frontals.-Normally an unpaired scale or scales occupying the space between middle and anterior halves of the semicircles defined by the orbits (Peters, 1964:131). In some individuals of Echinosaura, the frontal can be divided longitudinally (paired) or transversely into anterior and posterior segments. Distinguishing a fragmented posterior portion of the frontal from the scales normally termed frontoparietals would be difficult unless geographic markers related to the orbit were used, and our descriptions have been expanded to reflect this need.

Frontoparietals.-Paired or multiple scales lying posterior to the frontal and between the posterior halves of the semicircles and anterior to scales in the parietal and interparietal regions. The frontoparietals of Echinosaura are variable in size and number and consequently are difficult to distinguish from fragments of the frontal and the similarly variable parietal scales located posterior to them. As noted above, the definition of these scales is problematic, and we have limited our description of frontoparietals in taxa discussed in this study to "the scales bordering the posterior margin of the frontal" even though frontoparietals and parietals may be clearly identified in other groups of gymnophthalmid lizards.

Interparietal and Parietals.-Unpaired medial and paired scales, respectively, in the parietal region of the head are small and irregular in Echinosaura and Teuchocercus. They are present and easily identifiable in species of Neusticurus except in Neusticurus apodemus.

\section{RESULTS}

Status of Echinosaura spp.-Uzzell considered two specimens from Paramba, Prov. Imbabura, Ecuador, intermediate between horrida and palmeri because they had the paravertebral crest separated in two distinct rows, two internasals, snout short, frontal short, spines on the dorsolateral region of the neck not greatly elongate, and spines of lateral neck short. The presence of two internasals in conjunction with a short snout and short frontal prompted us to hypothesize that these specimens represented Teuchocercus keyi, and this identification was confirmed by examination of the specimens by one of us (SS). Thus, no intergrades are known from the Paramba locality.

Uzzell considered two specimens from Isla Gorgona, Colombia as intergrades between $E$. horrida and Echinosaura palmeri because they had paravertebral rows in contact and a single internasal (like horrida), but they differed in the degree of development of spines on the neck and in the form of the frontoparietal, characteristics which are difficult to assess and which we find to vary within single localities. We examined an additional specimen from Isla Gorgona (MCZ 160153) and find it to agree with E. horrida in characteristics of the paravertebrals and internasal. Thus, we identify the lizards from Isla Gorgona as a previously unreported population of horrida in Colombia and note the lack of evidence of intergradation between E. horrida and E. palmeri.

No intergrades between E. palmeri and Echinosaura panamensis were noted by Uzzell (1965), but he considered "the differences between them to be slight." We noted a striking difference in the structure of the tail in these taxa. The tail of palmeri is similar to that of horrida in having longitudinal rows of enlarged scales in the paravertebral, dorsolateral, and lateral regions of the tail. The rows are made of series of enlarged scales increasing in size from the anterior border of each autotomic segment to the posterior border of the segment and then repeating the pattern on the successive segments. The tail of horrida (illustrated by Fritts and Smith [1969:fig. 2]) is typical of the condition existing in palmeri. The tail of panamensis lacks continuous longitudinal rows because the scales on the anterior margins of each autotomic segment are small in size and similar to adjacent scales. At the posterior margin of the segments, enlarged scales exist in the paravertebral, dorsolateral, and lateral regions, but the successively smaller scales anterior to these enlarged scales grade into the small scales anteriorly, dis- 
rupting the rows. Most specimens of panamensis also differ from palmeri and horrida in having the frontal divided transversely and irregularly fragmented. One specimen from Panama (USNM 203665) has an entire frontal but retains the caudal morphology typical of panamensis.

Thus, we find evidence to suggest that the three taxa recognized by Uzzell (1965) as subspecies are best recognized as distinct species. The recognition of E. panamensis as distinct from E. palmeri is tentative based on the material available to us, but careful revision of these lizards with additional material will be needed to further clarify their status.

Distributional Relationships.-To date none of the three taxa has been reported to occur in sympatry, but the possibility exists near the Ecuador-Colombia border where E. horrida is known from lowland localities and E. palmeri is known from higher elevations.

Echinosaura horrida and T. keyi occur in sympatry at El Placer, Esmeraldas Province, Ecuador; USNM 196093 and USNM 196094 represent the two taxa, respectively. They also occur in sympatry at Mataje, Esmeraldas Province (NMW 31999 and NMW 32001:1, respectively) and at La Florida, Pichincha Province (KU 218389-395 and KU 218397-98, respectively). The specimens of Teuchocercus from Pichincha, Carchi, and Esmeraldas Provinces (listed in the Specimens Examined) augment our knowledge of the distribution of the species, which until recently was known only from the holotype and paratype of the species collected at the type locality in Pichincha Province of Ecuador. Teuchocercus keyi is readily distinguishable from Echinosaura in having a markedly shorter snout, wider head, prefrontal scales irregularly present, and in adults, the conical caudal scales noted in the original diagnosis by Fritts and Smith (1969). It also has granular scales covering the tympanum of adult specimens, but the small scales are not visible on the central part of the tympanum in small juveniles.

A morphologically distinctive and undescribed taxon of Echinosaura is known to occur in close proximity to (but not necessarily in sympatry with) horrida in Esmeraldas Province of Ecuador, near the Colombian border in the Mataje Region where Teuchocercus is now known to occur. We name this species in honor of Gustavo Orces V. in recognition of his contribution to the knowledge of the vertebrates of Ecuador and his guidance of students and other investigators over several decades.

\section{Echinosaura orcesi sp. nov.}

Figure 1

Holotype.-AMNH 109822; adult male collected by C. W. Myers (CWM 11457); Type Locality:
Colombia: Valle: approximately $13 \mathrm{~km}$ west of Dagua, Rio Anchicaya drainage, $820 \mathrm{~m}$.

Paratypes.-EPN 2574; adult female; Ecuador: Provincia Esmeraldas: Centro Comunal Mataje, Reserva Awa, near Rio Mataje at point where it parallels Rio Mira, $01^{\circ} 12^{\prime} 04^{\prime \prime} \mathrm{N}, 78^{\circ} 33^{\prime} 42^{\prime \prime} \mathrm{W}, 250$ $\mathrm{m}$; collected by Ana Almendáriz on 6 February 1988. NMW 32000:1; adult male; Ecuador: Provincia Carchi: San Marco, $670 \mathrm{~m}$; collected by E. Samec in 1988. NMW 32000:2; adult female; Ecuador: Provincia Carchi: San Marco, 700 m; collected by E. Samec in 1988.

Diagnosis.-A species of the genus Echinosaura with an extremely long snout, unpaired internasal, reduced numbers of supralabials and infralabials, enlarged caudal scales arranged in continuous transverse rings spanning the dorsal and lateral surfaces of the tail at the posterior margin of each autotomic segment; and elevated numbers of subdigital lamellae on the fourth toe. In contrast to other members of the genus, Echinosaura orcesi lacks continuous rows of slight to moderately enlarged scales in the paravertebral area of the body.

Description (based on holotype).- - Scales of head rugose with numerous longitudinal ridges; snout elongate, narrow; head markedly wider at and posterior to orbital region. A single internasal scale, longer than wide, with prominent longitudinal rugosities, medial groove, and a convex posterior margin, bordered posteriorly by a pair of frontonasals and laterally by posterior extension of rostral and anterior half of nasal scales. Frontonasals only slightly longer than the sum of their widths, marked with longitudinal rugosities, bordered posteriorly by convex anterior margin of frontal scale at level of presupraocular scales. Frontal narrowing posteriorly at middle of orbits, with a convex posterior margin at suture between first and second supraoculars contacting paired scales in frontoparietal region. "Frontoparietals" bordered laterally by second supraoculars and by most medial of a series of enlarged scales bordering posterior margin of orbits. Scales posterior to "frontoparietals" and on rest of posterior head small, irregular, flattened in medial occipital region, somewhat convex and tubercular in temporal region.

Nasal scale about twice as long as high with nóstril in middle; groove extending from nostril to border of internasal. A single scale slightly longer than high separates nasal from the anterior angle of orbit. Three supralabials, with suture between first and second just anterior to posterior edge of nasal, suture between second and third just anterior to middle of eye. Three infralabials. Mental extending further posterior than rostral; a single postmental bounded posteriorly by a pair of enlarged scales that laterally 

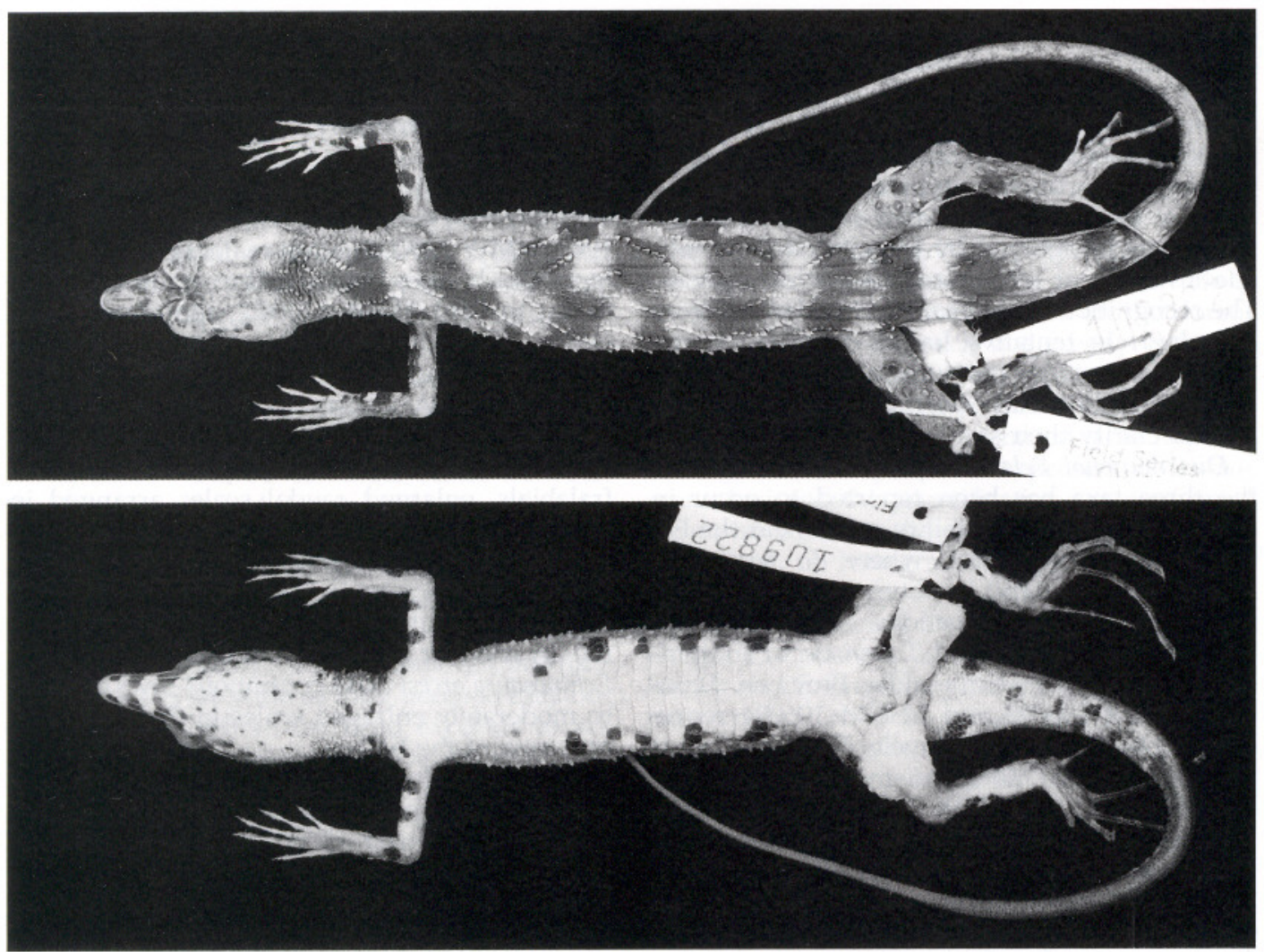

FIG. 1. Dorsal and ventral views of AMNH 109822, the holotype of Echinosaura orcesi.

contact second infralabials. All other scales on chin and gular region irregularly arranged, small. Tympanum small, lacking scales on surface but having tiny white flecks.

Scales of neck and body small, granular, not in transverse or longitudinal rows, intermixed with enlarged tubercular scales with longitudinal keels. Enlarged scales often arranged obliquely in short series of 3-8 scales forming irregular chevrons on dorsal field of body and broken undulating rows of scales along dorsolateral body. No continuous vertebral or paravertebral rows of enlarged scales. Chevrons extend onto base of tail only; tail incomplete, regenerated posterior to basal four autotomic segments. Scales on original tail small, irregularly arranged except at posterior margin of each autotomic segment where enlarged keeled scales are arranged in transverse series extending from paravertebral area laterally to longitudinal crease on lateral surface of tail. Scales anterior to the enlarged scales only slightly enlarged relative to granular caudal scales covering most of each caudal segment. Scales on regenerated segment of tail granular, uniform in size, irregularly arranged. Ventral scales loosely arranged in transverse rows between pectoral and pelvic regions and in eight longitudinal rows at midbody. Ventrals smooth, except for traces of keels on some scales at lateral margin of venter. Digits of hands and feet five, with prominent claws. Dorsal surface of upper forearm with enlarged, keeled scales; dorsal surface of lower forearm with smaller, keeled scales. Subdigital lamellae on fourth finger 20; lamellae on fourth toe 30 . Femoral pores 15-15 extending onto pelvic areas with $4-5$ scales separating right and left series of pores. About 44 scales on midline of venter from collar fold to vent.

Color in Life.-Dull brown with vague black dorsal bands (on neck, body, and base of tail). Venter dull yellow with black transverse bands across chin; a weak suffusion of white (individual granules) under head posterior to chin markings. Iris brown with heavy gray suffusion. Anterior part of tongue black, posterior part unpigmented. Description from field notes of C. W. Myers 28 January 1973.

Color in Preservative.-Black transverse markings on chin outline off-white markings coinciding with sutures between infralabials. White marks at suture between second and third in- 
fralabials extend dorsally to suture between second and third supralabials and to ventral margin of orbit. Tip of mental off-white. Lower eyelid unpigmented, translucent. Six irregular black blotches on each side of ventrolateral body with trace of white spot between consecutive pairs of dark blotches. A pair of smaller dark blotches and corresponding white spot is evident anterior to larger blotches, posterior to pectoral region. A broad white band at base of tail. Diffuse white markings on sutures of supraocular scales.

Notes on Variation.-The four specimens at hand are adults, two females and two males. The number of femoral pores differs between the sexes: males with $14-15$ pores on each side, females with 5-6 on each side. The width of the head is greater in the holotype and less markedly so in the other male (MNW 32000/2); the head of females is narrow. The three specimens with complete tails have long tails $(2 \times$ snoutvent length, SVL). Ratios of SVL/Tail length for the two females were $0.50-0.51$ and 0.45 for one male. Males were 69-70 mm SVL, females 76$81 \mathrm{~mm}$.

Presence of prefrontal scales between the paired frontonasals and the unpaired frontal is variable with two specimens lacking prefrontals, one having a pair of prefrontals, and one having a single prefrontal on only one side with the frontal and frontonasal in contact on the other side. Supralabials are 3-4 and infralabials $2-3$. Subdigital lamellae on the fourth toes are 30-31.

Arrangement of enlarged tubercles on neck, body, and head varies slightly. All individuals lack discrete rows of enlarged scales in the vertebral or paravertebral areas. Enlarged tubercles in the dorsal field are arranged in irregularly paired diagonal series that commonly produce tubercular chevrons. Three individuals have tubercular scales along the dorsolateral line arranged in a broadly undulating nearly complete tubercular crest. The type differs in having the scales in the dorsolateral area arranged in discontinuous and obliquely oriented series.

Color pattern of the paratypes is more diffuse than in the holotype. All animals have a prominent off-white band across the base of the tail, conspicuous white marking across the orbit and interorbital area, and the black-and-white markings on the infralabials and chin. Only the type has conspicuous dark blotches in the ventrolateral region of the body.

\section{DisCUSSION}

Comparisons with Other Echinosaura.-Echinosaura orcesi differs markedly from other Echinosaura in having a more elongate snout, reduced numbers of infralabials and supralabials, in- creased number of subdigital lamellae on the fourth toes, enlarged scales of dorsal and lateral surfaces of the tail arranged in transverse whorls at the posterior margin of each autotomic segment, and in lacking a distinct vertebral crest or paravertebral crests. Echinosaura orcesi is unique in its tail scutellation (consisting of continuous transverse rows of enlarged scales on the dorsal surface of the tail), lack of a continuous vertebral or paravertebral crest, and large number of femoral pores for females. Overall it has a less spinose appearance than other species of the genus Echinosaura.

The elongate snout of $E$. orcesi relative to that of other species is evidenced by ratios of the frontonasal length/internasal length. This ratio was $0.63: 0.80$ for $E$. orcesi versus 1.2:3.0 for individuals of other species. The ratio of frontal length/internasal length is also diagnostic with ratios of 0.85:1.0 for orcesi and 1.4:4.0 for other species. Potentially, the tail of orcesi is longer with SVL/TL ratios of 0.45:0.51 versus 0.56:0.95 for other species.

Echinosaura horrida from Ecuador differs in having a conspicuous vertebral crest formed by two adjacent and continuous rows of enlarged and somewhat elevated scales, a short single, unpaired, internasal (as opposed to an elongate one) and a short frontal, fewer subdigital lamellae on the fourth toe, a shorter tail relative to the body length, a shorter snout, moderatesized scales in the frontoparietal region that do not extend past the posterior margin of the supraoculars, tail ornamented with longitudinal rows of enlarged scales that alternate in size on each autotomic segment with scales on the posterior margin of each segment larger than the gradient of scales anteriorly; enlarged scales not in contact transversely at the posterior margin of the autotomic segments. Echinosaura horrida appears to lack the conspicuous white band on the base of the tail.

Variation in Echinosaura horrida.-The number of supraoculars was noted by Uzzell to vary from two to three. In specimens with three supraoculars, the first and second are large and the third is considerably smaller. In specimens with two supraoculars, the third is absent or sufficiently small to be confused with supernumerary scales at the posterior margin of the orbit. We found two supraoculars in all specimens from Ecuadorian localities in the Provinces of Imbabura and Esmeraldas and three supraoculars in most specimens from the Province of Pichincha. Ratios of SVL/Tail Lengths were 0.56:0.95. Supralabials 4:5; infralabials $3: 4$.

The new species resembles $E$. panamensis from Panama in lacking enlarged scales on the anterior portions of the autotomic segments of the tail but differs in having enlarged scales ar- 
ranged in nearly continuous rings at the posterior margin of the autotomic segments and in having an undivided internasal. Panamanian specimens are also similar in lacking a vertebral row and in having a sinuous pattern of enlarged scales in the paravertebral region; they differ in having the enlarged scales on the central dorsum in relatively continuous rows instead of being broken into irregular diagonally oriented series. Echinosaura panamensis also differs in having numerous enlarged scales on the lateral body arranged in obliquely angled rows instead of the sparse enlarged scales of $E$. orcesi, which do not contact each other and are arranged in extremely diffuse horizontal rows. Echinosaura panamensis has SVL/TL ratios of 0.66:0.91; five supralabials; and 5 infralabials.

Echinosaura palmeri differs from E. orcesi in having paired internasals, in tail scutellation, in having continuous paravertebral rows of enlarged scales, and in tending to have the frontal divided transversely. Echinosaura palmeri has SVL/TL ratios of 0.56:0.60; $5: 6$ supralabials; four infralabials.

The new species differs from Teuchocercus in having a much more elongate snout, in lacking continuous paravertebral rows, and in lacking conical scales on the tail that are separated by granular scales. Most Teuchocercus have paired internasals.

Variation in Teuchocercus keyi.-Although some variation exists, the cephalic scutellation typically consists of paired internasals, frontonasals, and prefrontals with a relatively short single frontal ending anterior to the level of the second supraocular. A pair of scales between the second supraoculars bounds the frontal posteriorly and is bounded posteriorly by small irregular scales. Three supraoculars are present with the third much smaller than the others. Superciliary scales separate the second and third supraoculars from the ciliary row along the border of the eye.

Infrequently the internasal is single instead of paired; it is wider than long. The presence of prefrontals in the presupraocular region is variable. The frontal is variable, depending on prefrontal condition, short, usually ending anterior to the second supraocular. One specimen (EPN2715) differs significantly in having a single internasal, a medial scale posterior to the frontonasals, and a fragmented frontal (apparently irregularly divided longitudinally and transversely). Teuchocercus have granular scales that cover some or all of the tympanum peripherally, but juveniles and subadults have a portion of the tympanum exposed medially. All show a reduced amount of the tympanum exposed relative to Echinosaura. Four juveniles have SVL of $24-27 \mathrm{~mm}$ and tails $28-43 \mathrm{~mm}$. The internasal is paired in all specimens examined except EPN2715. Prefrontal scales appear on one or both sides in nearly all specimens. The scales of the subcaudal region are relatively large and arranged in series of three scales per autotomic unit, even near the base of the tail. The scales on the ventrolateral tail are small but not granular. The enlarged scales on the dorsal and lateral tail are arranged in six longitudinal rows primarily at posterior margin of each autotomic segment. The prominence of the paravertebral rows increases with age and size. Paravertebral rows are separated by $2-4$ scales and weakly undulating. Subadult and juvenile specimens exhibit a prominent white band at the base of the tail and diffuse white bands on all sutures between supraoculars, but these characteristics were not evident in the adults comprising the type material (Fritts and Smith, 1969). The ventral coloration is variable with bold dark brown and white checkered pattern or only diffusely marked.

Acknowledgments.-We are grateful to the curators and staff of the various institutions allowing access to the specimens and data in their care and especially to C. W. Myers for information and photographs for the type specimen. J. Carr and R. Reynolds provided helpful comments on drafts of the manuscript. T. Uzzell and N. Scott also provided useful reviews.

\section{Literature Cited}

FrITTS, T. H., AND H. M. Smith. 1969. A new teiid lizard genus from western Ecuador. Transactions of the Kansas Academy of Science 72:54-59.

HARRIS, D. M. 1994. Review of the teiid lizard genus Ptychoglossus. Herpetological Monograph 8:226275.

KIZIRIAN, D. A. 1996. A review of Ecuadorian Proctoporus (Squamata: Gymnophthalmidae) with descriptions of nine new species. Herpetological Monograph 10:85-155.

OftedAL, O. T. 1974. A revision of the genus Anadia (Sauria, Teiidae) Arquivos de Zoologia. (São Paulo) 25:203-265.

Peters, J. A. 1964. Dictionary of Herpetology. Hafner Publishing Co., New York.

Uzzell JR., T. M. 1965. Teiid lizards of the Genus Echinosaura. Copeia 1965:82-89.

Accepted: 20 October 2001.

\section{APPENDIX 1}

Additional Specimens Examined

Echinosaura horrida.-Ecuador: Pichincha Prov: USNM 196100, near Pacto; MCZ 149670-71, Santo Domingo de los Colorados; MCZ 149670-149671, Santo Domingo de los Colorados; EPN 2711-13, Santo Domingo de los Colorados; USNM 196095-97, 196099, 257160-175, Dyott's Farm, km 121, 6 km east of Santo Domingo de los Colorados; KU 154666-67, 6 km east of Santo Domingo de los Colorados; USNM 283530, 
Rancho Santa Teresita, km 25 on road to Chone, Santo Domingo de los Colorados; USNM 285471-72, Centro Cientifico Rio Palenque, $47 \mathrm{~km}$ south of Santo Domingo de los Colorados; MCZ 145600, Centro Cientifico Rio Palenque; MCZ 156145, 156147, 156149, Logo Creek, Centro Cientifico Rio Palenque; KU 152598152599, Estacion Biologica Rio Palenque, $56 \mathrm{~km}$ north of Quevedo, 220 m; MCZ 145600, Centro Cientifico Rio Palenque, 47 km south of Los Rios; MCZ 156844, Centinella, $14.1 \mathrm{~km}$ southeast of Patricia Pilar; USNM 285680-81, El Centinela, on the crest of Montañas de Ila, $14.1 \mathrm{~km}$ east-southeast of Patricia Pilar, 550-600 m; MCZ 171866, 4 km east-southeast of El Esfuerzo; MCZ 171869, 6 km east-southeast of El Esfuerzo; KU 218389-395, $5 \mathrm{~km}$ west of La Florida, $860 \mathrm{~m}$; EPN 2710, Rio Saloya; Esmeraldas Prov:: USNM 196093, 1.5 km west of El Placer, 405 m; EPN2605, Caserio El Pan, Estero El Pan; NMW 31999:1, Rio Mataje; EPN 2609, 2649, 2614, Centro Comunal Mataje, Reserva Awa, 250 m; EPN 2716, no further locality; BMNH 1901.3.29.25, St. Javier; Imbabura Prov: KU 133503-133504, Lita; BMNH 1901.3.29.85, Rio Lita; NMW 16950:1-16950:3, Lita; Manabí: KU 218396, 38 km northwest of El Carmen, ca El Carmen-Pedernales Rd., 330 m; "Ecuador, Prov. unknown": NMW 19982:2-19982:8, no further locality; Colombia: Depto. Cauca: MCZ 160153, Isla Gorgona.

Echinosaura orcesi.-Colombia: Depto. Valle: AMNH 109822, approximately $13 \mathrm{~km}$ west of Dagua, Rio Anchicaya drainage, $820 \mathrm{~m}$; Ecuador: Esmeraldas Prov:: EPN 2574, Centro Comunal Mataje, near Rio Mataje, $01^{\circ} 12^{\prime} 04^{\prime \prime} \mathrm{N}, 78^{\circ} 33^{\prime} 42^{\prime \prime} \mathrm{W}, 250 \mathrm{~m}$; Carchi Prov.: NMW 32000:1, San Marco, 670 m, NMW 32000:2, San Marco, $700 \mathrm{~m}$.

Echinosaura palmeri.-Panama: Darien Prov: USNM
141789, Rio Tapalisa, 546 m; KU 113612-16, Rio Jaque, $1.5 \mathrm{~km}$ above Rio Imamado, $50 \mathrm{~m}$; KU 112617, ridge between Rio Jaque and Rio Imamado, 730 m; KU 113618, northeast slope Cerro Sapo, 820 m; KU 113620, north end Serrania de Pirre, $320 \mathrm{~m}$; KU 113621, Rio Tuira at Rio Mono, 150 m; KU 113622, southeast slope Cerro Pirre, 1520 m; KU 76165, Laguna, $820 \mathrm{~m}$; KU 76167-68, Tacarcuna, $550 \mathrm{~m}$; San Blas Prov: KU 113619, Camp Sasardi, 12 m; Colombia: Depto. Boyaca: USNM 127097-98, Muzo region; Depto. Valle: USNM 151621, Virology Field Station, Rio Raposo near Buenaventura; KU 144149, Quebrada La Guinea, $2 \mathrm{~km}$ east of Cisneros, $400 \mathrm{~m}$. Colombia: Depto. unknown: BMNH 1923.10.12.14, no specific locality.

Echinosaura panamensis.-Panama: Veraguas Prov: USNM 266154, Los Girasoles Escuela Agricola Alto Piedra, $5 \mathrm{~km}$ northwest of Santa Fe; Canal Zone: USNM 92594, Canal, Rio Grande; Cocle Prov: KU 76169-170, El Valle, 560 m; Darien Prov: USNM 50144, Pirri Range, head Rio Limon; Panama Prov: KU 80584, Finca La Sumbadora, 570 m; MCZ 127854127855, MCZ 127763, Cerro Campana; ANSP 21593, Cerro Campana, 909 m; ANSP 21087, El Valle, 606 m.

Teuchocercus keyi.-Ecuador: Esmeraldas Prov: USNM 196094, $1 \mathrm{~km}$ west of El Placer, $400 \mathrm{~m}$; NMW 32001:1, near Mataje, 350 m; NMW 31988, Rio Sabalera, 620 m; NMW 32001:9-32001:11, Rio Mira, 620 m; EPN 2717, 2719-720, Alto Tambo, 570 m; EPN 2718, Rio Sabalera; Carchi Prov.: EPN 2715, El Pailon, $78^{\circ} 14^{\prime} 11^{\prime \prime} \mathrm{W}$; $01^{\circ} 00^{\prime} 07^{\prime \prime} \mathrm{N}$; NMW 32001:2-32001:4, Rio Sabalera, near Ojala, 630 m; NMW 32001:5, Ojala, 400 m; NMW 32001:6-32001:8, Rio Sabalera, 620 m; Imbabura Prov:: BMNH 98.4.28.48-98.4.28.49, Paramba; Pichincha Prov.: KU 218397-98, 5 km west of La Florida, $860 \mathrm{~m}$. 